\title{
Familial Alzheimer's Disease
}

\author{
A.D. Sadovnick, H. Tuokko, A. Horton, P.A. Baird and B.L. Beattie
}

\begin{abstract}
A family with familial Alzheimer's disease (FAD) inherited as an apparent autosomal dominant trait is presented. Twelve individuals ( 6 females; 6 males) in 4 generations were affected. The disease had its onset in the late 30 's, early 40's with death by age 50. Although FAD which appears to be transmitted as an autosomal dominant trait is relatively rare, such families must be identified and carefully counselled with respect to recurrence risks for subsequent generations. In this family, there are currently 20 members of Generation IV, aged 15-37, and 9 members of Generation V, aged 1-11. The majority of these individuals appear to have a $50 \%$ risk for developing this disease.
\end{abstract}

RÉSUMÉ: Maladie d'Alzheimer familiale Nous présentons le cas d'une famille atteinte de maladie d'Alzheimer familiale dont l'hérédité semble être autosomale dominante. Douze individus, 6 femmes et 6 hommes, sur 4 générations étaient atteints. Le début de la maladie survenait vers la fin de la trentaine ou le début de la quarantaine avec décès avant l'âge de cinquante ans. Même si la maladie d'Alzheimer familiale qui semble être transmise de façon autosomale dominante est relativement rare, de telles familles doivent être identifiées et avisées du risque pour les générations suivantes. Dans cette famille, il y a actuellement 20 individus de la génération IV entre 15 et 37 ans et 9 individus de la génération $\mathrm{V}$ entre 1 et 11 ans. La majorité de ces individus semble être à risque, estimé à $50 \%$, de développer cette maladie.

Can. J. Neurol. Sci. 1988; 15:142-146

Alzheimer's disease (AD) accounts for $50-65 \%$ of patients with dementia. AD is characterized by an insidious onset, a steadily progressive course, and involvement of many areas of cognition in an individual who is otherwise alert, healthy, and free of motor or other neurological signs.' In these cases, computed tomography (CT) shows mild to moderate cortical atrophy and enlarged ventricles, the electroencephalogram (EEG) is diffusely slow, and cerebrospinal fluid (CSF) is normal.' In patients with $\mathrm{AD}$, positron emission tomography (PET) has shown a distinct decrease in cerebral metabolism compared with age-matched controls. ${ }^{2}$

The first descriptions of familial AD (FAD) were by Flügel ${ }^{3}$ and Schottky. ${ }^{4}$ Until very recently, there has not been a way of identifying familial and non-familial cases of this disorder other than by reference to the family pedigree. ${ }^{5}$ Some authors have interpreted pedigrees with multiple cases over several generations as representing autosomal dominant inheritance. ${ }^{6.7}$ Twin studies $^{8}$ in families which do not have FAD have shown discordance in monozygotic twins, suggesting that non-genetic factors play a role in these families. Multifactorial inheritance has also been postulated to explain the clusters of cases seen in some families. ${ }^{9.10}$ The importance of consanguineous matings as a causative factor in familial cases was noted by Lowenberg and Waggoner. " A preponderance of affected individuals of Ashkenazi Jewish ancestry has been observed in FAD. ${ }^{12}$
FAD has been the subject of exciting recent advances in research. Using genetic linkage and DNA markers in 4 large pedigrees, St. George-Hyslop et $\mathrm{al}^{7}$ showed that the genetic defect in these families is mapped to chromosome 21 . While rare, with only approximately 50-60 well-documented pedigrees showing autosomal dominant inheritance published to date, ${ }^{13}$ FAD may provide important clues to the etiology of $\mathrm{AD} .^{14}$

The purpose of this report is to present a large Canadian pedigree where AD appears to be segregating as an autosomal dominant disorder and to discuss genetic counselling for subsequent generations.

\section{Family Overview}

In this family (Figure 1), AD appears to be inherited as an autosomal dominant trait with 12 affected members ( 6 females; 6 males) in 4 generations. This family was ascertained through the proband (index case) who was referred to the Clinic for Alzheimer's Disease and Related Disorders (Alzheimer's Clinic). All Clinic patients have detailed genetic histories taken by a geneticist (A.D.S.).

The family is of Irish and Scottish ancestry and emigrated to Ontario in the 1820 's where many still reside. AD appears to have its onset in this family in the late 30 's or early 40 's. To date, all affected individuals have died by age 50 . There are no cases of consanguineous matings.

\footnotetext{
From the Departments of Medical Genetics (Drs. Sadovnick and Baird), Psychology (Dr. Tuokko), Psychiatry (Dr. Horton), and Medicine (Dr. Beattie), University of Eritish Columbia, and the Clinic for Alzheimer's Disease and Related Disorders, Health Sciences Centre Hospital, Vancouver, British Columbia

Received October 1, 1987. Accepted in final form February 11, 1988

Reprint requests to: Dr. A.D. Sadovnick, Department of Medical Genetics, University of British Columbia, 6174 University Blvd., Vancouver, British Columbia, Canada V6T IW5
} 


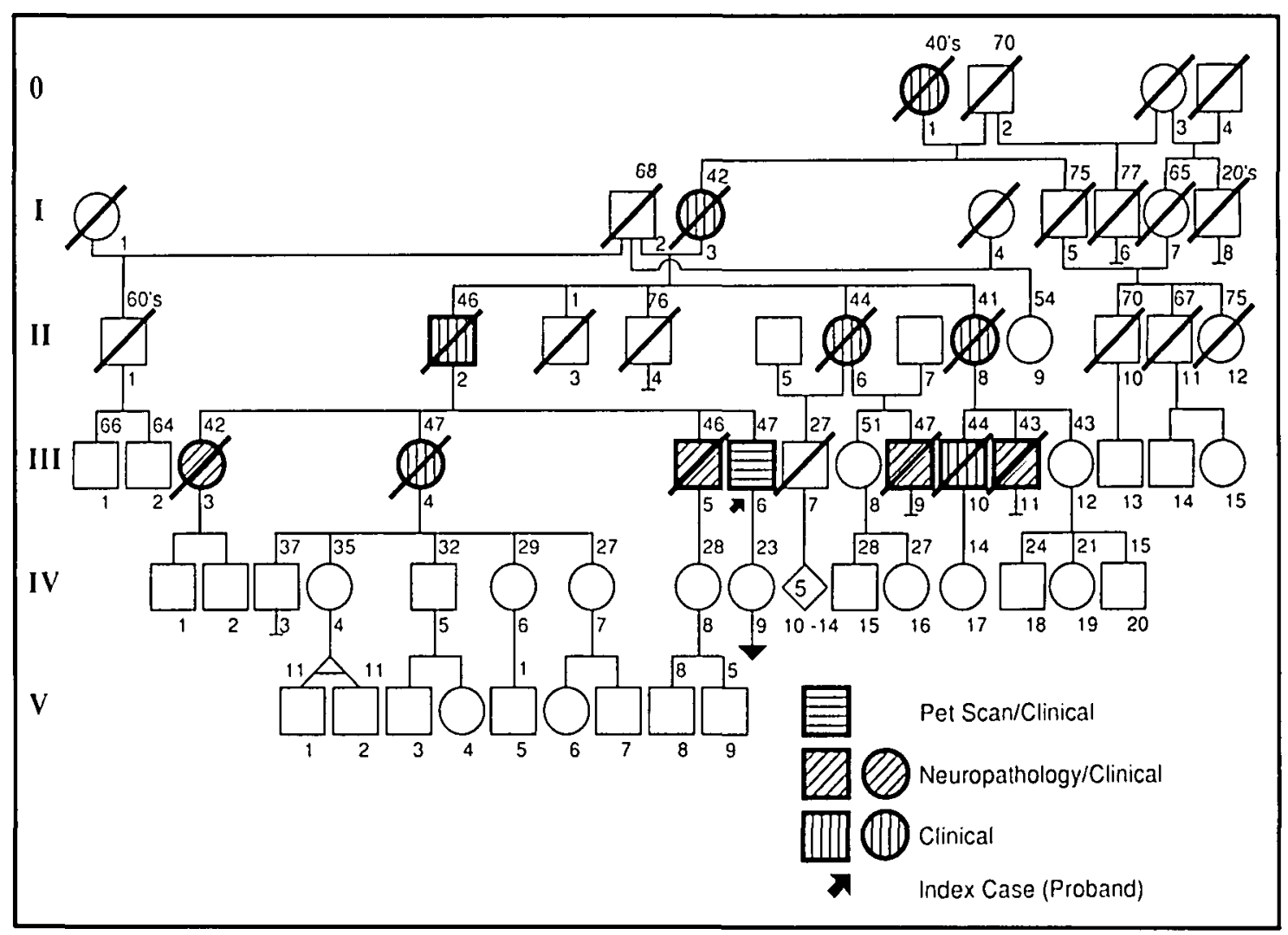

Figure 1 - Pedigree of a Canadian Family with Familial Alzheimer's Disease.

\section{Case Reports}

The data on affected individuals are summarized in Table 1.

\section{Subject III-6 (Proband)}

The proband (III-6) was born in 1940. He first developed symptoms of AD at age 40 when he was on an extended trip and became disoriented with respect to date and destination. He worked as a salesman and an announcer for a radio station. In his role as salesman, he alienated clients by calling them several times a day and being very repetitive in his conversation. When working as a radio announcer, he lost his ability to "ad lib" during live broadcasts. At age 44, he was no longer able to work and shortly thereafter stopped driving.

He initially presented at the Alzheimer's Clinic in April, 1985. He had previously been diagnosed as having "pseudodementia" caused by anxiety because of his family history. Past medical history revealed a possible myocardial infarction in his 30's and an episode of unipolar depression in 1984 .

At the time of initial assessment at the Clinic, no major medical problems were identified. He was living at home and able to do household chores. He was fully oriented, cooperative, and pleasant. Receptive and expressive language skills were unimpaired. Psychiatric diagnosis was dementia and unipolar depression in remission. A PET scan was done and the results were abnormal showing predominantly bilateral parietal involvement. Glucose utilization was decreased in the parietal and temporal lobes.

Reassessments were done in April, 1986 and May, 1987. At the second assessment, neurological examination showed progressive memory loss, apraxia, aphasia, and difficulty with abstract reasoning. At the final assessment, he was still living at home but his spouse had stopped work in order to care for him. He was hostile, agitated, and aggressive. He was disorientated with respect to time and place, had marked expressive language deficits, and could not comprehend simple oral or written instructions. On neurological examination, limb apraxia and primitive reflexes were noted. Active tremor of the hand and (jumpy) jerky movements of the arms were also observed, probably action myoclonus. Approximately 10 days after this last assessment, he had an episode of aggressive and uncontrollable behavior. He is presently in a high security provincial psychiatric institution.

As part of the routine diagnostic evaluation in the Clinic, he had the following psychological measures of cognitive functioning:

1. The Multi-Focus Assessment Scale (MAS) which measures social behavior, auditory and visual receptive language, mental status, orientation, mood, expressive language, and accessibility for testing; ${ }^{16}$

2. The Weschler Adult Intelligence Scale (WAIS); age-corrected scaled scores; ${ }^{17}$

3. The Controlled Word Association Test which measures verbal fluency; ${ }^{18}$

4. The Finger-Tapping Test and Dynamometer, measures of fine motor speed and grip strength;

5. Item 227 (Visual Recall) from the Luria Nebraska Neuropsychological Battery (LNNB), modified to include copy and delayed recall; ${ }^{19}$

6. Cued Recall Procedure for Memory Assessment ${ }^{20}$

7. The Neurosensory Centre Comprehensive Examination for Aphasia (NCCEA) Visual Naming subtest. ${ }^{21}$

Table 2 summarizes the results from the above listed tests over the three assessments, illustrating the steady decline in his cognitive function.

\section{Subject 0-I}

The proband's great-grandmother reportedly had the same illness as her daughter (I-3). She died at approximately age $\mathbf{4 0}$.

\section{Subject $1-2$}

Subject I-2 was the grandfather of the proband. The proband's grandmother, $1-3$, was the second of his three wives. He died at age 68 and fathered a child (II-9) by his third wife at age 60 . His son from his first union (I-2) died in his 60's. This man had two sons, both of whom are still alive in their mid to late 60's. Subject 1-2's daughter from this third union is alive at age 54 . In addition, a family chronicle written in the 1930's indicated that his siblings, parents, aunts, uncles, and first cousins lived long and active lives. 


\begin{tabular}{lcccl}
\hline \multicolumn{5}{l}{ Table 1: Clinical Summary of Affected Individuals } \\
\hline \hline $\begin{array}{l}\text { Pedigree } \\
\text { Code }\end{array}$ & Sex & $\begin{array}{c}\text { Age of } \\
\text { Onset }^{\circ}\end{array}$ & $\begin{array}{c}\text { Age at } \\
\text { Death }\end{array}$ & $\begin{array}{c}\text { Neuropathological } \\
\text { Documentation }\end{array}$ \\
\hline $0-1$ & F & late 30's & 40 's & Not Done \\
I-3 & F & late 30 's & 42 & Not Done \\
II-2 & M & 36 & 46 & Not Done \\
II-6 & F & 38 & 44 & Not Done \\
II-8 & F & 39 & 41 & Not Done \\
III-3 & F & late 30 's & 42 & AD confirmed \\
III-4 & F & 38 & 47 & Not Done \\
III-5 & M & 40 & 46 & AD confirmed \\
III-6 & M & 40 & - & - \\
III-9 & M & 38 & 47 & AD confirmed \\
III-10 & M & $36-37$ & 44 & Not Done \\
III-11 & M & 40 & 43 & AD confirmed \\
\hline
\end{tabular}

${ }^{\mathrm{a}}$ In most cases, this reflects the age at which the informant first became aware of problems. The accuracy of this information varies with the proximity to the informant (e.g. spouse in the house; sibling living apart) and the age of the informant (adult, teenager, preteen) at the time of the onset.

'The proband is alive at age 47. Both PET and neuropsychological examinations support a diagnosis of AD.

\section{Subject I-3}

She appears to have introduced the AD gene into the family, having inherited it from her mother (0-1). Her illness became the "family secret" and was never discussed openly with the family. The onset was in her late 30's. She was institutionalized when her youngest child (I-7) was 4 and died shortly thereafter in approximately 1920 at age 42 . Her brother (1-5) and paternal half-brother (1-6) both died in their late 70's.

\section{Subject $11 \cdot 2$}

The father of the proband had the onset of his illness approximately 10 years prior to his death at age 46 . He was the first member of his generation to be affected. Initially, he was forgetful and would have episodes of violent or withdrawn behavior. His wife was extremely secretive and did not reveal the familial nature of his problem to their own children. In later years, the offspring had ambivalent feelings and distress about this handling of the situation. As a solution to the family difficulties, $\mathrm{I}-2$ eventually enlisted in the armed forces during World War II. Specific details are unclear but apparently the family was next informed that he was in a military hospital because of "severe shell shock". He did not recognize his wife when she visited. No autopsy was performed. After his death, there was trouble regarding his military pension when it was concluded that his odd behaviour was due to a family disease he inherited rather than shell shock. His wife reportedly fought this ruling and eventually a pension was awarded.

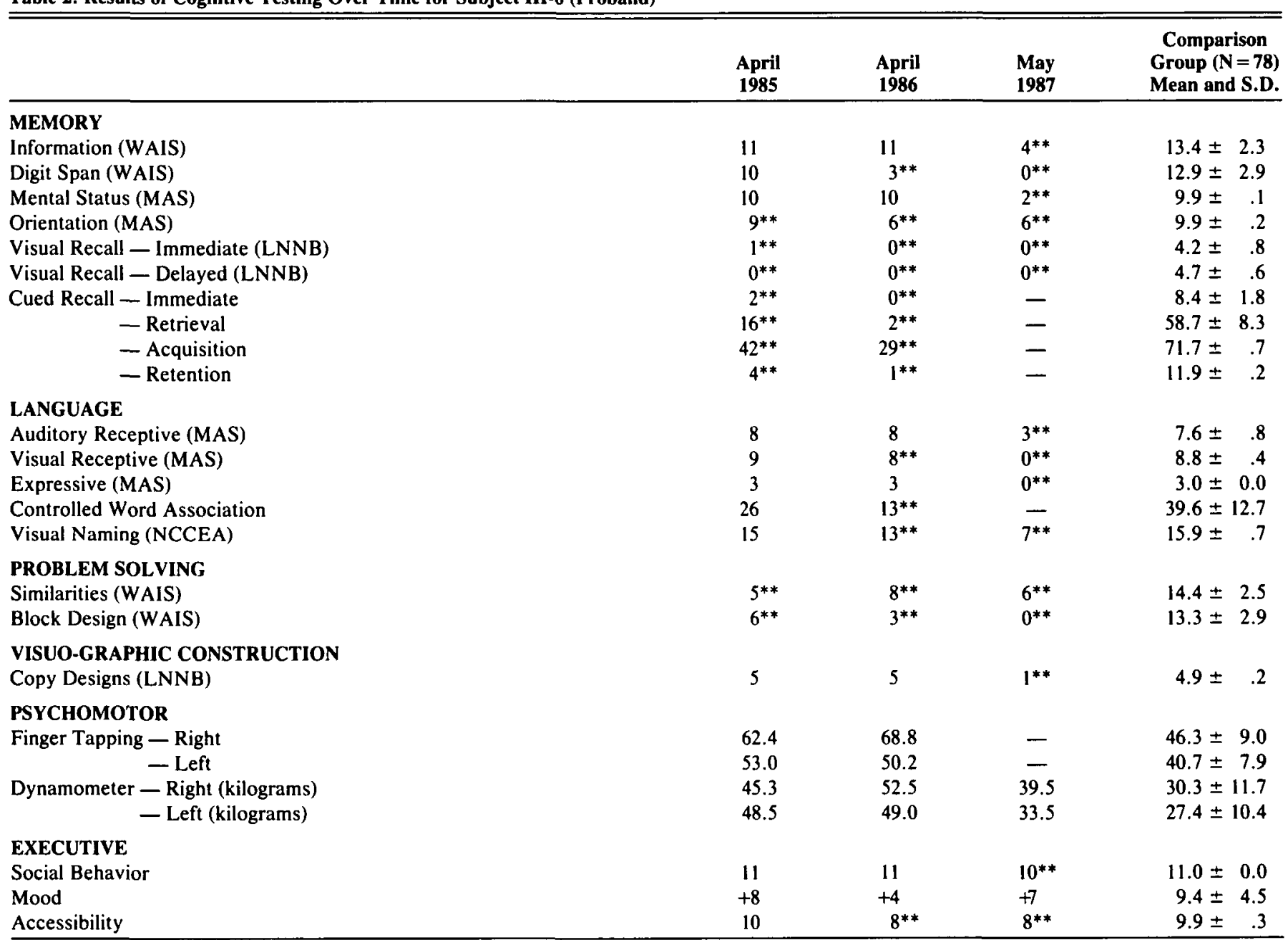

**Significantly below norm ( -2 standard deviations) for age-related peers (Beattie BL, Tuokko $\mathrm{H}$. Cognitive functioning in senior citizens. Bluma Tischler Postdoctoral Fellowship Report, University of British Columbia Faculty of Medicine, 1985.) 


\section{Subject II.3}

He died at age 76 from a myocardial infarction. He was clinically asymptomatic for $\mathrm{AD}$. Upon death, neuropathological examination was done and the results were entirely normal for his age. He had no children.

\section{Subject II-6}

She had the onset of her disease at approximately age 38 when her husband and children first noticed a decline in her ability to keep house. Initially, this was characterized by identical meals being served daily. The quality of the meals declined as did her general ability to care for the house and maintain personal hygiene. She became completely incapable of functioning both at home and in the community and could not recognize her family. She died at age 44 in a psychiatric hospital. No autopsy was done.

\section{Subject II-8}

Information from her daughter (III-12) indicates that her onset was at age 39 when she wandered off and also required her child's assistance with feminine hygiene. It is possible that more subtle problems began a few years earlier but the daughter, being under 10 , may not have noticed or remembered these. At age 40 , she was institutionalized and died at age 41 . Neuropathological examination was not done.

\section{Subject III-3}

Her problems were first noticed when, in her late 30's, her behavior became erratic and she lost the ability to care for her home. As her condition and behavior deteriorated, she entered a psychiatric hospital. The family was initially told that she had a brain tumor. She died at age 42 , reportedly during a brain biopsy. Results from the biopsy supported a diagnosis of AD. The cortex showed a very marked degree of patchy neuronal loss and normal neuronal lamination was markedly disrupted. Numerous senile plaques were observed. A large percentage of neurons contained basophilic neurofibrillary tangles and some had granulovacuolar degeneration. Diffuse and non-specific gliosis was observed in all layers of the cortex and there was some patchy, microglial proliferation, particularly in relation to senile plaques.

\section{Subject IIIA}

Her disease had its onset at approximately age 38. Memory loss and unusual behavior were initial symptoms. Psychological testing showed "global deterioration". She had previously suffered from a depressive illness in her 20's for which hospitalization was required. The depressive symptoms started when her sister (Il-3) became noticeably ill as she was certain that she was "next". For most of her later illness, she was cared for at home by her spouse and a housekeeper, but was institutionalized shortly before her death. Neuropathological examination was not done.

\section{Subject III-5}

An advertising manager, he was first noticed at age 40 to antagonize clients by being very repetitious. He went on to have memory problems and exhibited episodes of aggressive and violent behavior. As part of his medical investigation, his chromosomes were analysed and found to be normal. ${ }^{15} \mathrm{He}$ died at age 46 .

Neuropathological examination was done and the results supported a diagnosis of $\mathrm{AD}$. Brain atrophy (observed weight $1106 \mathrm{~g}$; expected weight $1400-1420 \mathrm{~g}$ ) was found and this was most prominent frontally. Coronal sections of the cerebrum confirmed atrophy. The gyri were sunken and the sulci widened. Lateral fissures were large. Lateral and third ventricles were dilated. The cortical ribbon was thin. The cerebral neocortex and allocortex had many senile plaques and neurofibrillary tangles. Plaques and tangles involved all layers of the cortex and all lobes. Neuronal loss and astrocytic gliosis were notable. The cortical and leptomeningeal arterioles showed congophilic angiopathy. Subcortical grey matter showed plaques and tangles. These were also present in the mammillary bodies and pallidum. Plaques were abundant in the septal nuclei. Tangles were noted in the substantia nigra, mesencephalic and interpeduncular nuclei, hypothalamus, thalamus, and nucleus basalis. The latter was also noted to be markedly deficient in neurons.

\section{Subject III-7}

The son of $1-5$, he died at age 27 from cancer, at least 10 years prior to the expected age of clinical onset for $\mathrm{AD}$ in his family. Neuropathological examination was not done at the time of his death.

\section{Subject III-8}

At age 51 , she is clinically asymptomatic and has probably not inherited the AD gene. After age 40, feeling that she had escaped the disease, she successfully completed nurse's training.

\section{Subject III-9}

A former trucker, he was initially observed to be disoriented on a European vacation at approximately age 38 . Subsequent to that, he began to forget to make scheduled deliveries and became increasingly forgetful. Neuropsychological testing showed a marked decrease in cognitive abilities, problems with language and visual spatial functioning, and impaired recent memory. A bachelor, he was institutionalized relatively early in the course of his illness. He died at age 47 .

The diagnosis of $A D$ was supported by the results of neuropathological examination. A moderate degree of cortical atrophy was observed, predominantly in the frontal and temporal regions. A large number of senile plaques and neurofibrillary tangles were found in all neocortical sections examined. Extremely severe changes were noted in the amygdala and hippocampus. In the latter site, there was also evidence of granulovacuolar degeneration and Hirano bodies. Cortical changes accompanied by conspicuous cell loss were observed, particularly in the superficial cortical layers. Cell loss and scattered tangles were seen in the nucleus basalis, substantia nigra, and locus coeruleus. Plaques and tangles were also present in the striatum and thalamus. Scattered tangles were found in the median raphe nucleus. Congo red stain on the inferior parietal area showed a deposition of amyloid in scattered leptomeningeal and neocortical vessels. There was evidence of amyloid angiopathy in the cerebellum.

\section{Subject III-10}

He also worked as a trucker and at approximately age 36 , he became lost while making deliveries. Subsequent to this, he became repetitious and would also lose track of the topic of conversation. He was institutionalized at age 41 and died at age 44 . Neuropathological examination was not done.

\section{Subject III-II}

His problems were first noticed at age 40 and were similar to those of his brother (III-10). He became lost and had difficulty following conversations. He was hospitalized at age 41 and died one month after his 43rd birthday. Neuropathological examination was done. A summary of the results indicated that there was moderate cortical atrophy, numerous neurofibrillary tangles and senile plaques throughout, and evidence of granulovacuolar degeneration.

\section{Subject III-12}

At age 43 , she reports that she is "fine, so far". However, it is of interest that relatives reported a recent decline in letter writing skills.

\section{Subjects IV-15 and IV-16}

These are the only 2 members of their generation who can at present be reassured that they probably have not inherited the ADgene, as their mother is asymptomatic at age 51 .

\section{Genetic Counselling}

This family appears to have autosomal dominant transmission of $\mathrm{AD}$. Evidence for this mode of inheritance includes (1) the risk to offspring of affected individuals is approximately $50 \%$, (2) there is no preponderance of one sex among affected individuals, (3) male-male transmission excludes $\mathrm{X}$-linked or 
cytoplasmic inheritance, and (4) complete penetrance seems to be present. AD appears to "run true" in this family with ages of onset and death consistent over the 3 generations. In addition, all affected individuals, including the proband, have deteriorated sufficiently to require hospitalization in a psychiatric unit.

Genetic counselling for this family raises many of the issues dealt with in counselling for another neurological condition, Huntington's disease. ${ }^{22}$ The onset of AD in this family is during the most productive years of life (late 30's and early 40's), at present there is no cure, prevention, or treatment, and children of "affected" or "at risk" individuals have their own risk shadowing their lives and influencing career, marital, and reproductive plans.

At present, all 20 members of Generation IV, with the probable exception of IV-15 and IV-16, likely have a $50 \%$ risk for developing $\mathrm{AD}$. In addition, there are to date 9 members of Generation V, including a set of monozygotic twins. The proband's daughter has just had a son.

If in the future, preclinical testing becomes feasible for some families with FAD as a result of DNA marker studies, ${ }^{7} \mathrm{mem}-$ bers of generations III and IV may have this option. However, as is the current situation for Huntington's disease, ${ }^{23,24}$ preclinical testing may become available before the prevention, cure, or treatment of $\mathrm{AD}$ is available. Persons then choosing to have preclinical testing will require appropriate support services. It is, of course, important to collect blood now from all available affected and unaffected family members, so that if predictive DNA testing becomes an option, it can be offered to subsequent generations.

It is of interest to note that several family members resented the fact that the familial nature of the disease was kept secret and stated that they would have altered career and family choices had they been aware of the situation. Now that members of generation III and IV are aware of the risks, several have decided to alter choices in their lives. A few have changed their careers and others have deliberately chosen not to have children.

In summary, although FAD is rare, it is important that thorough family histories be taken on individuals presenting with this disorder, so that high risk situations can be identified and appropriate counselling given.

\section{ACKNOWLEDGEMENTS}

This work was supported in part by the Alzheimer Society of British Columbia.

Drs. Noreen Rudd and Irma Parhad (Calgary, Alberta) and Michael Partington (Kingston, Ontario) were most helpful in documenting this family. The proband was also assessed by Drs. J. Stoessl and R. Peppard (Neurology), and Ms. M. Wong and Ms. E. Kosarek (Social Work). PET was done as part of a project supervised by Drs. P. and E. McGeer.

This work would not have been possible without the ongoing assistance of members of the family.

\section{REFERENCES}

1. Katzman R. Differential diagnosis of dementing illnesses. Neurologic Clinics 1986; 4: 341-353.

2. Benson DF. Neuroimaging and dementia. Neurologic Clinics 1986; 4: 341-353.

3. Flügel FE. Zur diagnostik der Alzheimerschen krankheit. Z Ges Neurol Psychiat 1929; 120: 783. (Cited by Feldman RG, Chandler KA, Levy LL, Glaser GH. Familial Alzheimer's disease. Neurol 1963; 10: 811-824.)

4. Schottky J. Über präsenile berblodungen. Z Ges Neurol Psychiat 1932; 140: 333. (Cited by Feldman RG, Chandler KA, Levy LL, Glaser GH. Familial Alzheimer's disease. Neurol 1963; 10:811-824.)

5. Heston LL. Clinical genetics of dementing illness. Neurologic Clinics 1986; 4: 439-446.

6. Heston LL, Lowther DL, Leventhal CM. Alzheimer's disease: a family study. Arch Neurol 1966; 15: 225-233.

7. St. George-Hyslop PH, Tanzi RE, Polinsky RJ, et al. The genetic defect causing familial Alzheimer's disease maps on chromosome 21 . Science 1987; 235: 885-890.

8. Nee LE, Eldridge R, Sunderland T, et al. Dementia of the Alzheimer type: clinical and family study of 22 twin pairs. Neurol 1987; 37: 359-363.

9. Sulkava R, Rossi L, Knuutila S. No elevated sister chromatid exchange in Alzheimer's disease. Acta Neurol Scand 1979; 59: 156-159.

10. Sjögren T, Sjögren H, Lindgren A. Morbus Alzheimer and morbus Pick: genetic, chemical, and pathoanatomical study. Acta Psychiatr Neurol Scand 1952; suppl 829: 1-152.

11. Lowenberg K, Waggoner RW. Familial organic psychosis (Alzheimer's type). Arch Neurol Psychiatry 1934; 31: 737-754.

12. Goudsmit J, White BJ, Weitkamp LR, et al. Familial Alzheimer's disease in two kindreds of the same geographic and ethnic origin: a clinical and genetic study. J Neurol Sci 1981;49: 79-89.

13. Davies P. The genetics of Alzheimer's disease: a review and a discussion of the implications. Neurobiol of Ageing 1986;7:459-466.

14. Barnes DM. Defect in Alzheimer's is on chromosome 21. Science 1987; 235: 846-847.

15. White BJ, Crandall C, Goudsmit J, et al. Cytogenetic studies of familial and sporadic Alzheimer's disease. Am J Med Genet 1981; 10: 77-89.

16. Coval M, Crockett D, Holliday S, Koch W. A multi-focus assessment scale for use with frail elderly populations. Can J on Ageing 1985; 4: 101-109.

17. Weschler D. Weschler Adult Intelligence Scale. Manual. New York: Psychological Corporation, 1955.

18. Benton AL. Differential behavioral effects in frontal lobe disease. Neuropsychologia 1968; 6: 53-60.

19. Golden CJ, Hammeke TA, Purisch AD. Manual for the LuriaNebraska Neuropsychological Battery. Los Angeles: Western Psychological Services, 1980.

20. Buschke H. Cued recall in amnesia. J Clin Exp Neuropsychol 1984; 6: 433-440.

21. Spreen O, Benton AL. Neurosensory Centre Comprehensive Examination for Aphasia. Victoria: Neuropsychological Laboratory, department of Psychology, University of Victoria, 1969.

22. Tyler A, Harper PS. Attitudes of subjects at risk and their relatives towards genetic counselling in Huntington's chorea. J Med Genet 1983; 20: 179-188.

23. Shaw, $M$. Testing for the Huntington gene: a right to know, a right to not know, or a duty to know. Am J Med Genet 1987; 26: 243-246.

24. Lamport AT. Presymptomatic testing for Huntington's chorea: ethical and legal issues. Am J Med Genet 1987; 26: 307-314. 